\title{
Китай, Россия и внешняя политика ШОС
}

\author{
Флемминг Сплидсбоел Хансен ${ }^{*}$
}

Можно сказать, что отпраздновав свой десятилетний юбилей в 2011 году, Шанхайская организация сотрудничества (ШОС) быстро поднялась на высокую позицию в мире региональных организаций. Часть причин этому кроется в успешном политическом маркетинге организации, процессе, в котором государства-члены открыто рекламируют свою амбицию создать азиатский блок, основанный на более широком и более глубоком сотрудничестве. Как было ясно указано в 2001 году в Декларации о создании ШОС, эта амбиция включает развитие внутри самой организации культуры «близкого сотрудничества по наиболее важным международным и региональным проблемам». ${ }^{1}$

Высокая степень согласия о целях и способах их достижения среди членов группы-что, собственно, и является предварительным условием для близкого сотрудничества в области внешней политики-будет означать, что они могут с готовностью сформировать фронт с единой политикой и таким образом им будет легче оказывать влияние на свое окружение. И наоборот, низкая степень согласия будет означать, что для них будет относительно трудно встать плечом к плечу и реализовать амбиции, заявленные в Декларации.

\section{Оценка сплоченности ШОС}

Далее следует оценка фактического уровня согласия по внешней политике в кругу стран-членов. Она включает главным образом шесть полноправных членов: Китай, Россия, Казахстан, Кыргызстан, Таджикистан (основавших в 1996 году Шанхайскую пятерку, предшественника ШОС) и Узбекистан, который присоединился к ШОС на учредительной встрече в 2001 году. ${ }^{2}$ К этой группе я добавил и четыре первых государства со статусом наблюдателя - Монголию (которая присоединилась в 2004), а так же Индию, Иран и Пакистан (все присоединились в 2005), - так как они являются наиболее вероятными кандидатами на полноправное членство. ${ }^{3}$

Я измеряю уровень согласия во внешней политике ШОС путем анализа результатов голосований десяти стран, членов и наблюдателей, в Генеральной ассамблее

\footnotetext{
* Флеминг Сплидсбоел Хансен, доктор философии, является директором по исследованиям датского оборонного колледжа в Копенгагене. Автор выражает благодарность за финансовую поддержку фонду «Карлсберг».

1 Шанхайская организация сотрудничества, «Декларация о создании шанхайской организации сотрудничества», 15 июня 2001; доступно на: www.sectsco.org/RU/show.asp?id=83.

2 Относительно Шанхайской пятерки и ШОС смотри: Flemming Splidsboel Hansen, "Тhe Shanghai Co-operation Organisation," Asian Affairs 39:2 (2008): 217-32.

3 Афганистану был предоставлен статус наблюдателя на саммите ШОС в Пекине в июне 2012 года; это решение было принято после написания данной статьи и поэтому результаты голосования Афганистана не были включены в набор данных.
} 
Объединенных наций. Результат голосования каждого государства рассматривается как заместитель его внешнеполитического поведения. Такие исследования проводятся с 1950-х и являются хорошо апробированной и часто используемой методологией, которая может предоставить нам количественную информацию в том случае, когда мы рассуждаем о возможных изменениях во внешней политике отдельного государства или в отношениях между двумя и более государствами. ${ }^{4}$

\section{Инструментарий}

Набор данных, который используется в этом анализе, это результат голосования стран, являющихся полноправными членами и наблюдателями ШОС, и он доступен для свободного пользования на сайте Объединенных наций. ${ }^{5}$ Чтобы представить более полную картину развития внешней политики в этих государствах, я расширяю времевой базис, используя данные сессий Генеральной ассамблеи с 47ой по 65-ю, начиная с сентября 1992 года и кончая июлем 2011 года. Это означает, что я включаю данные, относящиеся к периоду до учреждения ШОС и даже Шанхайской пятерки. В рамках этого времевого интервала я взял данные каждой второй сессии, что дало мне набор данных, относящихся к десяти различным сессиям.

Методология сбора данных опиралась на три основных принципа. ${ }^{6}$ Во-первых, я использовал только результаты голосования по резолюциям, которые прошли (таким образом исключая резолюции, которые были отвергнуты, а так же исключая голосование по отдельным частям резолюций). Во-вторых, из этого массива данных я включал результаты только поименного (регистрированного) голосования. Сочетание этих принципов дало подборку из более чем 700 зарегистрированных голосований. Результаты этих голосований формируют базис последующего анализа. Третий и последний принцип состоит в том, что неучастие в голосовании принимается за воздержание. В каждом из этих более 700 голосований страны, являющиеся членами или наблюдателями в ШОС, имели возможность проголосовать «За», «Против» или воздержаться. Существует, однако, и четвертая возможность, - просто отсутствовать, т.е. вообще не участвовать в голосовании.

Сталкиваясь с проблемой абсентеизма, некоторые исследователи просто отбрасывают все случаи, в которых в голосовании участвуют не все объекты анализа. ${ }^{7}$ Однако так как Узбекистан, Кыргызстан и Таджикистан в нескольких сессиях имеют очень высокий уровень абсентеизма, очевидно, такой подход не го-

4 Steven Holloway, "Forty Years of United Nations General Assembly Voting," Canadian Journal of Political Science 23:2 (1990): 279-96; и Erik Voeten, "Clashes in the Assembly," International Organization 54:2 (2000): 185-215.

5 Ha http://unbisnet.un.org.

6 Смотри: Paul Luif, "EU Cohesion in the UN General Assembly," Institute for Strategic Studies Occasional Papers 49 (2003): 22-23; и Elisabeth Johansson-Nogués, "The Voting Practice of the Fifteen in the UN General Assembly: Convergence and Divergence," Observatori de Politica Exterior Europea Working Paper 54 (2004).

7 Johansson-Nogués, "The Voting Practice." 
дится для данного исследования. Такой подход существенно уменьшит набор данных голосования, и более того, остающиеся голосования будут неравномерно распределены между отдельными сессиями, таким образом составляя весьма искривленную картину невысокой достоверности.

Вместо этого я принял неучастие за воздержание, приписывая соответствующему государству «среднюю» позицию. Основное предположение, на котором основывается этот принцип, состоит в том, что когда государство не участвует в голосовании, принимается предположение, что государство не знает, как голосовать - т.е. оно колеблется между «За» и «Против». ${ }^{8}$ Однако, если страна-член не принимала участие в более чем одной трети всех зарегистрированных голосований в отдельной сессии, данные этой сессии не включаются в набор данных за вопросный год.

Это правило применяется к трем различным странам-членам и к пяти отдельным сессиям. Особенно низкую дисциплину голосования на Генеральной ассамблее показал Таджикистан, и результаты голосований этой страны исключены из 47 и 51-57 сессий. Данные Узбекистана исключены из сессий 47 и 55-57, а Кыргызстана - из сессий 47 и 57.

\section{Общая картина}

Я начал с общей картины голосования ШОС в целом. Для этого данные были классифицированы в трех категориях в соответствии с расстоянием между государствами на шкале «Да - воздержался - нет». Первая категория включает случаи единодушного голосования, по результатам которых имелось полное согласие. Вторая категория содержит голоса, которые разделены на две группы (или частич-

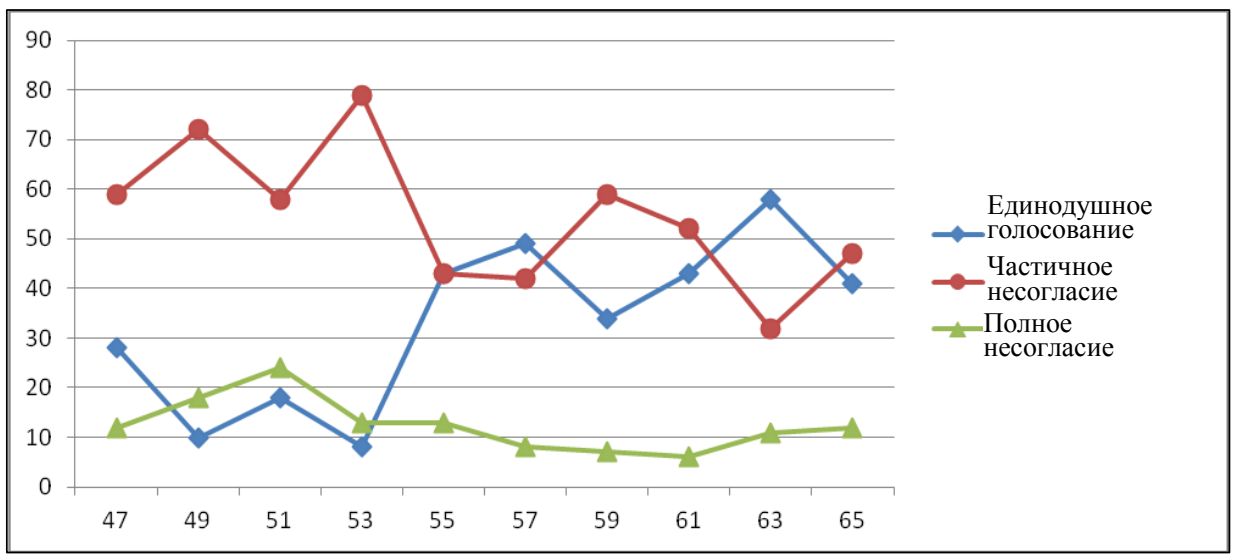

Фигура 1: Общая картина согласованности.

8 Luif, "EU Cohesion." 
ное несогласие), когда хотя бы одно государство воздержалось, тогда как другие проголосовали или «Да», или «Нет» (но не и то, и другое). Третья группа состоит из голосований, где голоса разделились на три группы (или полное несогласие), когда хотя бы одна страна проголосовала «Да», тогда как хотя бы одна другая проголосовала «Нет». ${ }^{9}$ Фиг. 1 показывает результат общей картины голосований (Ось $\mathrm{X}$ - сессия, ось Y - процент от общего числа зарегистрированных голосований).

Диаграмма показывает, что во-первых, доля единодушных голосований драматически колеблется с 1992 года по 2011 год, и что картина в действительности сложная. Частично это является результатом абсентеизма, который, к сожалению, искривляет данные. Если рассматривать в целом, за весь период наблюдается рост доли единодушных голосований на 13 процентов (от 28 процентов в 47 сессии до 41 процента в 65 сессии). Существует небольшое опасение, что это число было бы выше, если бы Кыргызстан, Таджикистан и Узбекистан не были исключены из набора данных 47 сессии из-за очень высокой степени неучастия. Поскольку их голосования в то время были умеренно пиковыми, они бы понизили уровень единодушия в этой первой сессии и таким образом увеличили бы рост доли единодушных голосований за все десять сессий.

Присмотревшись более пристально только к сессиям 57-65 - т.е. за 2002-2011 годы - мы увидим, что доля единодушных голосований в действительности уменьшилась на 8 пунктов. Как будет показано ниже, Узбекистан проводил внешнюю политику, которая в конце 1990-х делала его весьма отличающимся в смысле голосований в этой группе. Если бы данные Узбекистана были включены в набор данных за 57 сессию, действия только этой страны дали бы уменьшение единодушных голосований до 14 процентов (от 49 процентов) и увеличение доли частично единодушных голосований до 78 процентов (вместо 42 процентов). Числа для 55 сессии были бы соответственно 12 и 75 процентов, вместо 43 и 45 процентов. Но надо иметь ввиду, что эти числа имели бы высокую степень неопределенности, так как большой процент голосований Узбекистана, которые были включены, в действительности были неучастием (которое принималось за воздержание).

Однако, имея ввиду голосования Узбекистана до этого периода, есть серьезные основания полагать, что эта страна в действительности продолжила бы демонстрировать (хотя возможно и более умеренно) сильную независимость, которой характеризовалась ее внешняя политика в период, предшествовавший ее решению вступить в ШОС в 2001 году (смотри табл. 1). Это не только отдалило бы увеличение доли единодушных голосований, но и выровняло бы их, таким образом увеличивая авторитет ШОС как гомогенизирующего фактора. В результате нам следовало бы ожидать, что если голосования Узбекистана были бы включены в набор данных за 57 сессию, общая картина показала бы, что страны ШОС фактически увеличили-а не уменьшили-число единодушных голосований с 2002 по 2011 год.

9 Johansson-Nogués, "The Voting Practice," 4. 
Абстрагируясь, однако, от этих рассуждений, мы видим, что сессии 59-65, которые включают данные о всех десяти странах, показывают среднюю долю единодушных голосований в 44 процента (при изменении от 34 до 58 процентов). Для сравнения, ЕС систематически регистрирует гораздо большую, чем 75 процентов, долю единодушных голосований - и это при гораздо большей группе участвующих государств. ${ }^{10}$ Мало что в картине после 2001 года заставляет предполагать, что ШОС будет в состоянии достичь похожий уровень единодушия в своем втором десятилетии путем социализации или конъюнктурного голосования, при котором более слабые государства следуют за более сильными с целью получить выгоды или избежать наказания.

Эти данные так же показывают разные уровни несогласованности. Доля случаев, когда голоса разделены в двух группах, варьирует почти обратно пропорционально доле единодушных голосований, и на ней проблема абсентеизма отразится подобным образом. Этот тип несогласованности (в отличии от полной несогласованности) показывает, что определенное государство отдает предпочтение политике по определенному вопросу, которая только слегка отличается от той, что предпочитает большинство. Результат голосования, однако, предполагает так же, что менее сильное государство может не иметь желания противоречить сильным государствам напрямую, что привело бы к разделению голосов на три группы. Интересно отметить, что Таджикистан, Кыргызстан и Монголия-государства, которые являются относительно слабыми странами в смысле возможностей-имеют картину соотношения голосований, в которой голоса разделялись на две и на три группы, непропорционально смещенную в сторону первого. Сильно зависимые от своих партнеров по ШОС, может быть, эти государства пришли к заключению, что свое инакомыслие лучше демонстрировать умеренно.

Уровень полного несогласия среди стран-членов и стран-наблюдателей был относительно невысоким. Достигая максимума в 18 и 24 процента в сессиях 49 и 51 соответственно, в целом он остается относительно близко к отметке в 10 процентов. Эта общая картина означает, что страны-члены и наблюдатели имели прямо противоположные точки зрения только в одной десятой из всех голосований. Случаи, в которых голоса распределились по трем группам, были в основном созданы поведением Индии и России, которые оставались в меньшинстве в этих случаях гораздо чаще, чем остальные государства. Тогда как Индия действовала так в течении всего рассматриваемого периода, Россия оставалась в меньшинстве в таких случаях в течении 1990-х. После изменения политики, продиктованного российским президентом Владимиром Путиным в начале 2000 -х, голосования России сместились ближе к среднему, и с тех пор она бывала причиной разделения голосов на три группы в гораздо меньшем числе случаев. Полное несогласие в основном провоцировалось голосованиями по вопросам безопасности (особенно по нераспространению ядерных вооружений и по разоружению) и раньше по вопросам, связанными с правами человека, когда Россия голосовала в полной изоля-

10 Там же., 6; и Luif, "EU Cohesion,” 28. 
Таблица 1: Расстояние полноправных членов и стран-наблюдателей от среднего для ШОС.

\begin{tabular}{lcccccccccc}
\hline & $\mathbf{4 7}$ & $\mathbf{4 9}$ & $\mathbf{5 1}$ & $\mathbf{5 3}$ & $\mathbf{5 5}$ & $\mathbf{5 7}$ & $\mathbf{5 9}$ & $\mathbf{6 1}$ & $\mathbf{6 3}$ & $\mathbf{6 5}$ \\
КИТ & 5 & 5 & 3 & 7 & 3 & 3 & 3 & 2 & 5 & 3 \\
ИНД & 4 & 11 & 11 & 13 & 6 & 8 & 8 & 8 & 9 & 8 \\
ИРН & 3 & 11 & 9 & 9 & 3 & 5 & 5 & 5 & 7 & 6 \\
КАЗ & 17 & 7 & 13 & 7 & 11 & 12 & 3 & 5 & 4 & 3 \\
КЫР & н/д & 11 & 15 & 10 & 7 & н/д & 5 & 4 & 2 & 11 \\
МОО & 6 & 2 & 6 & 7 & 5 & 11 & 6 & 9 & 8 & 4 \\
ПАК & 3 & 2 & 3 & 7 & 4 & 4 & 4 & 5 & 5 & 5 \\
РОФ & 26 & 20 & 20 & 13 & 8 & 12 & 8 & 6 & 9 & 10 \\
ТАД & н/д & 15 & н/д & н/д & н/д & н/д & 8 & 7 & 3 & 7 \\
УЗБ & н/д & 9 & 26 & 28 & н/д & н/д & 16 & 9 & 3 & 5 \\
\hline
\end{tabular}

н/д - нет данных

ции от других стран группы по декларациям, осуждающих нарушителей прав человека, включая даже Иран.

\section{Осредненные результаты для ШОС}

Картины голосования, представленные на фиг.1, дают информацию о ШОС в целом; они не говорят ничего о поведении отдельных государств. Мы можем найти информацию об этом, рассмотрев средний или «осредненный» результат голосований и вычислив отстояние каждого государства от этой величины. Я получил это число, идентифицировав все голосования, в которых имелось абсолютное большинство среди стран-членов и наблюдателей ШОС, включенных в массив данных от разных сессий. Стандартное абсолютное большинство составляет 50 процентов плюс один - т.е. шесть государств. Однако, поскольку некоторые государства были исключены из-за неучастия, абсолютное большинство варьирует; в сессиях 47 и 57 это только четыре государства, тогда как в сессиях 51-55 - пять.

Если государство составляет часть абсолютного большинства, оно получает оценку 0 ; если оно голосует против абсолютного большинства в случае, когда голоса разделились на две группы (частичное несогласие), оно получает оценку 1/2; и если оно голосует против абсолютного большинства в случае, когда голоса разделились на три группы (полное несогласие), оно получает оценку 1. Далее сумма оценок представляется в виде доли (в процентах) от общего числа регистрированных голосований за данную сессию. Результаты представлены в табл. 1 (0 - минимальное расстояние, 100 - максимальное расстояние).

Числа показывают в целом сходимость к среднему, независимо, измеряется ли она как величина максимального отклонения (от 26 процентов в сессии 47 до 11 
процентов в сессии 65) или средним расстоянием (от 9.1 процента в сессии 47 до 6.2 процента в сессии 65). Если рассматривать изолированно сессии 59-65, они показывают ту же тенденцию, хотя развитие не так очевидно. Есть легкое расхождение в период 2009-2011 год, но на основании этого короткого времевого базиса нельзя сделать никакие определенные заключения.

Мы видим, что Китай определенно ближе к среднему поведению при голосовании, чем любая другая страна-член или страна-наблюдатель ШОС. В семи из десяти сессий эта страна находится на самом близком отстоянии от среднего значения со средним отклонением в 3.9 пункта, то есть ее позиция олицетворяет «линию внешней политики ШОС». За ним следуют Пакистан и Иран (со средним отстоянием в 4.2 и 6.3 пункта соответственно).

Являясь ведущей страной в том, что Ерик Воетен назвал «анти-гегемонной группой» в мировой политике, Китай вел целостное слияние мнений внутри ШОС в то же самое анти-западное направление. ${ }^{11}$ Эта политика отвергает предполагаемую универсальность актуальных для Запада вопросов демократии и прав человека и вместо этого делает упор на уважение к традиционному суверенитету государств и на соблюдении принципа невмешательства во внутренние дела других наций. ${ }^{2}$ Реализуя максимальное отклонение в 7 пунктов за весь исследуемый период (и в двадцать первом веке не превышающий и 5 пунктов), Китай дает нам картину страны, которая стоит там, где она решила стоять, наблюдая с этой позиции, как другие страны в целом приближаются к ней.

Этот анализ также показывает, что Россия является отьявленным инакомыслящим. В четырех из десяти сессий эта страна имеет наибольшее отстояние от средней позиции по голосованию. Со средним расстоянием за десять сессий в целых 13.2 пункта, Россия находится позади только непредсказуемого Узбекистана. Как видно из табл.1, результаты голосований последнего были весьма драматическими-смещаясь от высокой степени несогласия к высокой степени конформизма - со средним отстоянием за семь сессий в 13.7 пункта. На третьем месте, но на относительно большом расстоянии, находится Индия со средним отстоянием в 8.6 пункта. Рассматривая сессии 59-65 отдельно, мы видим, что со средним отклонением в 8.3 пункта эти три государства идут нога в ногу в соревновании за место главного девианта от средней для ШОС позиции.

Как видно из табл.1, Россия только в части случаев стремится к более консенсусной позиции. Важно добавить, что этот сдвиг к среднему явился скорее результатом изменений в российской политике, упомянутых выше, чем результатом какого-то процесса, благодаря которому другие государства постепенно начали голосовать как Россия. ${ }^{13}$ После передефинирования Путиным, что такое хорошо и

11 Voeten, "Clashes in the Assembly," 213.

12 Alastair Iain Johnston, "Is China a Status Quo Power?," International Security 27:4 (2003): 556.

13 Александр Чубарян, «Основные этапы внешней политики России», в сборнике Десять лет внешней политики России, под ред. Анатолия Торкунова (Москва: РОССПЕН, 2003), 26-32. 
что такое плохо в мире, страна сохраняет частоту отклонения от среднего для ШОС поведения на уровне 8-12 процентов.

Изменения в политике России и Узбекистана, стран, которые раньше весьма отклонялись от среднего поведения при голосовании, конечно, могут где-то в будущем пойти в обратную сторону, но похоже, что в последние годы эти два государства определили более стабильно свои политические предпочтения. В России они отражают идеи так называемой суверенной демократии, которая является основой как внутреннего так и международного мировоззрения, поддерживаемого Путиным. ${ }^{14}$ В Узбекистане эти предпочтения связаны с еще более фундаментальным вопросом - выживанием режима президента Ислама Каримова. ${ }^{15}$ Пока узбекский режим чувствует себя под угрозой давления Запада с упором на расширение демократических свобод и улучшение положения, касающегося прав человека, мы можем ожидать, что он весьма лояльно будет следовать за своими более могучими союзниками из ШОС.

\section{Перспективы}

Картина внешней политики ШОС разнообразна. С одной стороны, ясно, что в целом страны-члены и страны-наблюдатели голосовали все более схожим образом с 1992 года, когда все пост-советские страны-члены были приняты в ООН. Такое же развитие наблюдается и в сессиях 59-65, для которых существуют данные о всех десяти государствах, хотя за этот период процесс конвергенции более медленный и непрямой. Данные не могут показать нам, какова причина этой сходимости социализация или давление, или когда и как это случилось. Необходимо более детальное изучение отдельных государств, прежде чем мы сможем сказать что-нибудь определенное относительно этого сдвига.

Так как картина голосования становится все более согласованной, риск для отдельного государства связать себя нежеланным близким сотрудничеством уменьшается; просто вероятность того, что оно окажется в уязвимой позиции меньшинства или будет вынуждено пойти на компромисс по важным политическим вопросам, уменьшается. Продолжающаяся конвергенция предполагает, что ШОС будет все легче расширять и углублять политическое сотрудничество и в том числе предоставить наблюдателям статус полноправных членов.

С другой стороны, замедление процесса конвергенции означает, что странычлены и страны-наблюдатели достигли рубежа, который некоторые из них не захотят пересечь. Что остается общим между ними, это смешанный набор основных предпочтений-к примеру, по правам человека, по ядерному развитию, по оружейным технологиям-которые разные альянсы государств продолжат соблю-

14 Разные статьи в сборнике под ред. Леонида Полякова, Про современную демократию (Москва: Европа, 2007).

15 Matteo Fumagalli, "Alignments and Realignments in Central Asia: The Rationale and Implications of Uzbekistan's Rapprochement with Russia," International Political Science Review 28:3 (2007): 256-57. 
дать. Устойчивость голосований, при которых голоса разделялись на три группы в течении 2000-х, подсказывает тот же вывод.

К этому надо добавить такой важный факт, что Россия остается государством, наиболее часто имеющим особое мнение. Процесс конвергенции обеспечивается Китаем, и не будет преувеличением сказать, что Пекин доволен этим в большей степени, чем Москва. Оживленные политические дебаты в Москве показывают растущую озабоченность тем, что страна теряет силу по сравнению с Китаем и в результате теряет влияние в пост-советской Центральной Азии. ${ }^{16}$ Конвергенция, о которой шла речь выше, при которой Центральная Азия склоняется в сторону Китая, может вызвать у политиков России колебания по вопросу, связывать ли себя более близким сотрудничеством с членами ШОС или по вопросу о расширении ШОС. То, что хорошо для Китая-и может быть и для остальных стран-членов ШОС-конечно же, не обязательно хорошо и для России.

16 Для обсуждения, смотри: Александр Лукин, «Цена вопроса», Коммерсант (17 июня 2011); доступно на: www.kommersant.ru/doc/1660857. 


\section{Литература}

Chubaryan, Aleksandr. "Osnovnye etapy vneshnei politiki Rossii." In Desyat let vneshnei politiki Rossii, 26-32. Moscow: ROSSPEN, 2003.

Deklaratsiya o sozdanii shankhaiskoi organizatsii sotrudnichestvo. Shanghai Coooperation Organization, 2001.

Fumagalli, Matteo. "Alignments and Realignments in Central Asia: The Rationale and Implications of Uzbekistan's Rapprochement with Russia." International Political Science Review 28, no. 3 (2007): 256-57.

Hansen, Flemming Splidsboel. "The Shanghai Cooperation Organisation." Asian Affairs 39, no. 2 (2008): 217-32.

Holloway, Steven. "Forty Years of United Nations General Assembly Voting." Canadian Journal of Political Science 23, no. 2 (1990): 279-96.

Johansson-Nogués, Elisabeth. The Voting Practice of the Fifteen in the UN General Assembly: Convergence and Divergence In Working Paper. Observatori de Politica Exterior Europea , 2004.

Johnston, Alastair Iain. "Is China a Status Quo Power? ." International Security 27, no. 4 (2003): 5-56.

Luif, Paul. EU Cohesion in the UN General Assembly. Occasional Papers . Institute for Strategic Studies, 2003.

Lukin, Aleksandr. "Tsena voprosa." Kommersant (2011).

Polyakov, Leonid. "Various contributions." In Pro suverennuyu demokratiyu. Moscow: Evropa, 2007.

Voeten, Erik. "Clashes in the Assembly." International Organization 54, no. 2 (2000): 185-215. 